\title{
Research on Regulatory Sandbox Setting for the Development Needs of Emerging Industries -- Illustrated by the Case of Bike-sharing
}

\author{
Duo Li \\ School of Economics and Management, Harbin Engineering University, Harbin 150001, China \\ 13170871585@163.com
}

\begin{abstract}
Under the background of the Fourth industrial Revolution, emerging industries have been developing vigorously. While injecting innovative vitality into the society, they have also exposed problems such as lack of supervision, difficulty in risk control and policy lag in current government governance. By sorting out the application effect and experience of "regulatory sandbox", a nascent governance tool, in different fields around the world, this paper analyzed the applicability and necessity of introducing "regulatory sandbox" into the regulatory system of China's emerging industries from the perspectives of innovation demand, regulatory philosophy and institutional logic. This paper chose the Bike-sharing industry which is extremely representative as the research object. and the "regulatory sandbox" model of Bike-sharing industry is designed to clarify the responsibilities of stakeholders such as the supervision subject, testing subject and participating user of the sandbox, and to explain the operation mechanism such as access, test and exit. Finally, this paper also analyzes the common problems of regulatory sandbox in the development of emerging industries and the special problems in the Context of China. Following this paper, the nascent governance tools such as "regulatory sandbox" and the supervision philosophy of agile governance should be applied to more emerging industries to achieve the goal of balancing innovation and risk, improve regulatory efficiency, and encourage emerging industries to exert a positive influence on society.
\end{abstract}

Keywords: Emerging Industries; Regulatory Sandbox; Bike-sharing; Agile Governance.

\section{Governance Challenges in the Development of Emerging Industries}

In recent years, thanks to the large scale of users and sound infrastructure [1]The fourth industrial revolution is in full swing in China, with the birth of a large number of emerging industries, formats and business models. These emerging industries are subverting the traditional laws and paths of industrial development, changing our lives in different ways and affecting the way we view the world. The emerging industry is the core driving force of technological innovation, the advantage lies in the creativity, able to organic integration of the different types of products and services, accurate matching market supply and demand, develop new products, new services beyond the value of traditional products and services, effectively to adapt to the requirements under the new economic era quality and demand breadth of an upgrade, to promote social welfare improvement.[2]

At the same time, the development of emerging industries also brings various governance challenges, which can be divided into three aspects: 1) The development of emerging industries is highly uncertain, which is reflected in the unclear technological development path, the disruptive business model, and the complexity of customer needs[3][4]. 2) The potential of risks makes it difficult to assess the regulatory costs and benefits of emerging industries, which increases the difficulty of formulating policies and rules related to risk regulation. Government departments cannot determine the risk distribution and probability function of emerging industries.[5]Moreover, some risk factors in the development of emerging industries, if not timely identified and controlled, are likely to lead to a large social cost; 3) It is difficult to measure the regulatory scale of the government for emerging industries, and the Chinese-style regulatory dilemma of "chaos after release and death after regulation" occurs frequently.[6] Because emerging industries are volatile, vulnerable to policy influence, and highly dependent on capital in the early stage,[2][5]The direction of policy can significantly affect market trends. If the government's various access permits and risk supervision 
work is too strict, it will raise the entry threshold and compliance costs of emerging industries, discourage the confidence of innovative enterprises and capital market, restrain the supply and development vitality, and thus hinder industrial innovation. The comprehensive development of emerging industries makes it more and more difficult for the traditional regulatory model to adapt to the "forced" government innovation governance model, the introduction of new regulatory tools, and the construction of multi-party participation of collaborative governance model.[6][7]

\section{The Effectiveness of Regulatory Sandbox}

"Regulatory sandbox" concept first by Britain's financial behavior regulator (FCA) is put forward in 2015, 2016 officially start the project application, mainly using the financial innovation of science and technology, to provide enterprises with a test product, service, innovation, business model and delivery mechanism security space, to cope with the financial and technology combining explosion brought by the new requirements, It also provides a way for regulators to view their regulatory framework and provide appropriate regulatory support. [8]The regulatory sandbox is based on disruptive innovation and adaptive regulation,[9]Designed to combine cutting-edge technologies such as artificial intelligence, machine learning, encryption and security, blockchain, and cloud computing,[10]It has the characteristics of differentiated regulation, flexible rules and peopleoriented, which can maintain the balance and stability between innovation and regulation. [11][12]Following the lead of the UK, more than 40 countries and regions, including Singapore, Denmark, Australia, and Hong Kong, have adopted or plan to adopt sandbox, a new regulatory tool, in innovative activities in different fields such as finance, energy, intelligent transportation and information, and communications. The regulatory sandbox originated from the regulation of fintech, and most countries and regions currently using the tool are also mainly used in the financial sector and derivatives. However, this does not mean that its use is limited to a specific industry. There are many successful cases in other areas.

The UK's Gas and Electricity Market Office (OFGEM) advocated the use of regulatory sandboxes in its innovative energy business proposals as early as February 2017, calling on OFGEM to adapt the regulatory framework to the future development of the UK energy industry. In October 2017, Singapore's Energy Market Authority (EMA) released a paper on the regulatory sandbox for the energy sector, encouraging more trials in the electricity and gas sectors. The document sets out the objectives and principles of the sandbox and the application process to provide EMA with a way to review existing regulations and make appropriate adjustments to meet actual needs so that valuable smart energy innovations can be scaled up. Singapore will review the framework a year after it was launched and discuss how to enhance it, launching version 2.0 of the Regulatory Sandbox framework for Singapore's energy sector in 2019.[8] South Korea has set up a special regulatory sandbox legal structure of "1+4 Law", which not only focuses on finance and financial extension but also covers a wider range of applications such as medical industry, information and communication industry, industrial integration, special economic zones for special regional development and so on.[14][15] Japan advocates a "project-based regulatory sandbox" regardless of industry, deeply integrates innovation with different industries, and tests the application of blockchain technology in medical clinical data monitoring[16]In addition, Sweden and other European countries have applied innovative regulatory tools such as regulatory sandbox and policy laboratory to urban intelligent transportation planning.[17]

(1) Enterprises and investors: Regulatory sandboxes are most popular with start-ups and companies not authorized by the current regulatory system. By clearly specifying the scope of trials and testing rules, screening and limited authorization of innovative projects can significantly reduce uncertainty in development, provide investment security for investors, and facilitate financing for innovative projects. About $40 \%$ of the companies in the FCA sandbox were funded during or after testing,[13]It has significant significance to promote the rapid growth of start-ups or small and medium-sized enterprises. 
(2) Consumer perspective: All participating enterprises in THE FCA sandbox abide by the sandbox rules, and only one has started the exit procedure. Regulatory sandboxes highlight the goals of protecting consumer rights and increasing access and improving the experience for vulnerable consumers. The risk tolerance of consumers should be fully considered before the test, and the rights and interests of consumers should be jointly safeguarded in the form of cooperation between regulatory bodies and enterprises during the test. In turn, it can test consumer acceptance and commercial viability of innovative projects, and one-third of the companies in the FCA sandbox have adjusted themselves accordingly.[13]

(3) Market perspective: Jayoung James Goo et al. (2020) conducted an empirical analysis from the perspective of investment scale in countries that adopted regulatory sandbox, and found that the total investment in countries that introduced regulatory sandbox increased by $37.7 \%$ over the previous year, and the average growth rate of investment was $86.4 \%$, proving the significant effect of the regulatory sandbox on promoting industry activity.[14]The case study also shows that the regulation of sandbox up all kinds of new technology utility ratio (such as distributed books DLT, online platform, application program interface technology APIs, biometrics, etc.), thus in the quality of innovative products and services improve, the price is lower and the user access has a positive impact, to effective played a significant role in market competition, There are still some potential risks.

(4) Supervision: On the one hand, different testing projects will be connected by a special person in charge (such as the CASE officer in the FCA sandbox) to help the company get familiar with the current regulatory framework and policy direction, provide personalized guidance for them, and cooperate to complete the test. Reports received by the FCA indicate that sandbox has significantly reduced the cost of regulatory consultants, business model transitions and accelerated the development cycle of innovative products. On the other hand, the FCA report also shows that continuous communication and feedback between the participating companies and the regulatory body can encourage the regulatory authorities to develop more precise and rigorous policies and procedures and optimize their regulatory tools. Therefore, the regulatory sandbox is not only a test of innovative projects but also a test of regulatory frameworks and policies.

As can be seen from many practical cases, the regulatory sandbox has developed different versions in different countries and regions and has proved its effectiveness for innovation development in different fields. At the same time, it has broken the original assumption that the regulatory sandbox only applies to developed countries and played to the advantage of many developing countries.

\section{The Applicability of Regulatory Sandbox in the Development of Emerging Industries in China}

Some scholars point out that the "regulatory sandbox" matches the needs of China's modern governance system, and the basic principle is like the implementation logic of China's pilot reform. It is necessary and feasible to establish a "regulatory sandbox" at the current stage.[18][19] Although the model is still in the conceptual stage in China, it has the basic conditions for preliminary implementation and the time is ripe.

Because of the applicability of regulatory sandbox in China, different domestic scholars have discussed it from different perspectives. Based on previous studies, this paper starts from the specific operation mechanism of the regulatory sandbox and a series of advantages such as combining risks and innovation, dynamic adjustment of rules, benign interaction between regulatory parties, and protection of stakeholders' rights and interests. The applicability of regulatory sandbox in the development of China's emerging industries is summarized as follows.

(1) Meeting the needs of building a modern governance system

Emerging industries are an indispensable part of the modern economic system. However, due to the high uncertainty, complexity, potential risks, and other characteristics of their development, they have brought severe challenges to the comprehensive adjustment of regulatory concepts and institutional structures to the government departments. From a technical point of view, the regulatory 
sandbox contains a data-sharing mechanism and an information platform, combined with intelligent risk control, multi-factor authentication, data desensitization, and other advanced technologies, which can monitor the development of the industry in real-time, obtain the development needs in a timely manner, dynamically adjust the sandbox rules, and realize the endogenous policy interaction.[18] When an enterprise has a deviation, the regulatory body can help it adjust its development strategy quickly with directional policies and reduce the silent cost. On the theoretical level, it can enhance the benign interaction between the two regulatory parties, create a good development environment for innovation, and achieve collaborative development. Therefore, the application of regulatory sandbox is in line with the policy goal of the reform of "delegating power, delegating power, delegating power, providing services", and meets the needs of China's current construction of a modern governance system.

(2) Be compatible with the development policy concepts and goals of emerging industries

The current regulatory concept and goal of emerging industries are to actively play its leading role in innovation, ensure that it is not killed by the traditional framework on the premise of risk management, to maximize the overall welfare of the society. Regulatory sandbox for growth and development of emerging industries provides the appropriate system of soil and tolerance test space, convenient and its rapid growth, but is not the same as "method", on the contrary regulation sandbox more improved protection of the rights and interests of the government's risk control ability and ability, to safeguard the rights and interests of all stakeholders, especially emphasizes the protection of consumers' rights and interests. In the operation of a sandbox, the sandbox focuses on protecting the legitimate rights and interests of consumers, and gradually improves the consumer protection system in the experiment, and forms a complete system from pre-evaluation to in-process monitoring, and then to post-disposal. Regulatory sandbox can also realize the upgrading of the protection concept of consumer rights and interests in China, from low-level "basic rights and interests protection" to highlevel "expected benefit protection".[10] In line with the policy concept and goal of improving public service level and protecting consumer rights and interests in the development policy of emerging industries.

(3) Logical convergence with the pilot setup of emerging industries

In essence, the regulatory sandbox is a trial process of innovation with rapid development and change but whose impact cannot be judged temporarily within a certain period of time, so as to judge whether the innovation has positive significance for social and economic development.[18] If through the trial, regulators determine the innovation can effectively improve the development efficiency and benefit consumers, so the government will further introduce the corresponding policies and regulations and support all kinds of resources, promote innovation in a larger scope of application, if found potential risks exist in the development, the timely guide the industry to adjust or exit. Shanghai, Zhejiang, Shenzhen, and Wuhan have set up pilot reform and innovation programs to promote the development of new industries, new forms of business, and new business models[25]Therefore, from this point of view, the regulatory sandbox is logically similar to the setting of technological innovation pilot in China's emerging industries, and also conforms to the implementation path of "pilot first, explore experience, and gradually promote". It is possible to explore the typical experience of alienation of business travel and the corresponding institutional model only through the policy pilot in different regions with different economic development, cultural tradition, and historical background.

(4) Ideal regulatory paradigm of emerging industries

For emerging industries with high innovation potential but potential risks, for emerging industries with no precedents and highly uncertain and changeable development paths, for emerging industries that have not met current regulatory requirements or lack relevant policy guidance, for emerging industries that lack testing approaches or have high testing costs, In the government departments to consider the project substantive test value, the future trend, and the current regulatory resources, on the basis of the regulation of sandbox can provide a test the safety of the space, in the process of the sandbox running, can not only realize to evaluate innovation project, also can test and optimization 
to the current policy is an ideal regulation paradigm.[20] Fintech, the representative field of regulatory sandbox application, is also driven by emerging frontier technologies such as big data, blockchain, cloud computing, and artificial intelligence under the background of the fourth industrial revolution, and is the product of deep integration of innovation.[10] It has the same characteristics as emerging industries, so this paper designs the regulatory framework of emerging industries based on practical cases.

\section{Design of Regulatory Sandbox Framework for Shared Bikes}

Bike-sharing is an emerging product of the concept of "sharing economy" in modern China, aiming to solve the "last mile" problem, and the development process has been ups and downs. On the basis of the development of the original urban public bike rental service, shared bikes, combined with advanced technologies such as mobile payment, satellite positioning, and electronic fence, began to show explosive growth in 2015, with a large influx of capital, covering more than 200 cities across the country. Contributed more obvious, at the same time, share the bike in the early 2017 "Shared cycling economic and social impact report shows Shared bicycle industry for people save 760 million hours of travel time, saving the haze governance costs 1.3 billion yuan, offers plenty of job opportunities, contribution to economic and social reached 221.3 billion yuan, has become the public preferred way to travel.[23] However, the good times don't last long. In the rapid development of the shared bike industry, various problems occur frequently, such as vicious competition, disorderly parking and deposit refund, etc., and the externality turns from positive to negative. In just three years, Bike-sharing has gone through ups and downs. In addition to the chaos within the industry, the government's supervision of Bike-sharing, an emerging industry, is not timely and agile. The introduction of the regulatory sandbox, an innovative regulatory tool, into the governance of the Bikesharing industry can avoid such problems, facilitate the realization of agile governance, and provide ideas for the regulation of similar emerging industries.

(1) Test process requirements

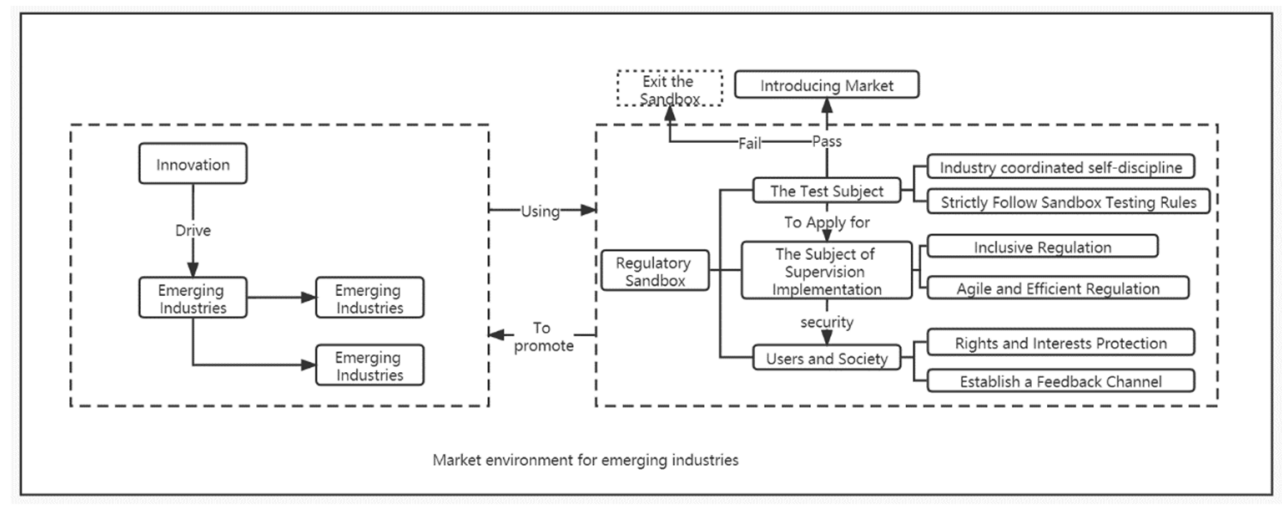

Fig 1. Framework of emerging industries regulatory sandbox

Firstly, the regulatory sandbox testing area, testing time, testing scale, and the number of users should be controlled. Sandbox testing projects should be concentrated as much as possible in the same area, and collaborative monitoring systems should be established across regions and markets. The FCA in the UK believes that sandbox testing should be limited to three to six months.[19] Local governments can set time limits based on the characteristics of the Bike-sharing industry and regional characteristics, and appropriately extend the testing period of some projects to reduce risks. The test scale and number of users of Bike-sharing projects should also be strictly controlled to ensure complete statistical data acquisition and to control the spread of risks.

Secondly, the requirements for testing products and services of shared bikes are stipulated. Bikesharing enterprises should choose projects that meet the sandbox market environment to apply for and should have substantial innovation. Regulatory bodies should screen all kinds of projects in real- 
time, and stop and withdraw Bike-sharing products, services, and projects that do not meet the requirements, are not suitable for testing, and exist fake innovation.

Finally, specify a clear exit mechanism. Before the sandbox test is over, Bike-sharing test companies are required to prepare for withdrawal in advance. If they want to extend the test period, they must apply and negotiate with the regulatory authorities in advance. If the test results are satisfactory, Bike-sharing enterprises can carry out project promotion in a wider range of markets after withdrawal. All the rules and provisions in the regulatory sandbox will expire after the company exits. Bike-sharing enterprises that voluntarily or passively quit due to failure to meet testing or regulatory requirements during the course of operation should conscientiously do a good job of withdrawal and further compensation for users.

(2) Functions of the competent department

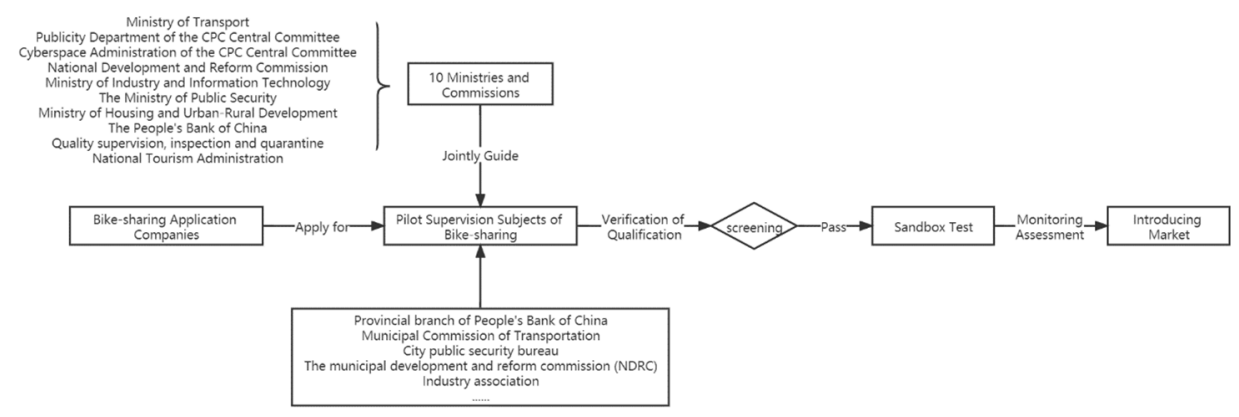

Fig 2. Design of regulatory sandbox framework for shared bikes

The development model of shared bikes is flexible and changeable, and the supervision involves the authority of multiple departments such as road planning, vehicle management, and financial supervision, which is different from traditional public bicycles (which are mainly under the responsibility of a single municipal department such as the Transport Committee or urban management Bureau). Drawing lessons from the regulatory sandbox in the UK, the US, Singapore, and other regions, the central level should play a good role in overall planning and guidance in the regulatory framework system of shared bikes.[18][10] The current Shared cycling is the Ministry of Transport, the central propaganda department is mainly responsible for the department, the central net letter office, the National Development and Reform Commission, Ministry of Industry and Information Technology, the Ministry of Public Security, housing urban and rural development, the People's Bank of China, national tourism administration of quality supervision, inspection, and quarantine, consisting of 10 ministries (shown in figure 2), has been jointly issued policy guidance, but cooperation between departments, Lack of targeted policy services.[24]

Therefore, based on the ten ministries and commissions, a joint regulatory body for Bike-sharing regulatory sandbox can be further established, and policy guidance can be issued according to the professional functions of the ten ministries and commissions to provide policy support for provincial subordinate institutions and point out the development direction of the regulatory sandbox. Provincial transportation hall, public security department, National Development, and Reform Commission, economic and information commission, safety supervision bureau according to local government departments and directly affiliated institutions, such as the central file build sandbox supervision of local Shared cycling steering committee, is responsible for the regional regulatory sandbox development plan, implementation of regulation in the province box for guidance and supervision.

Subordinate cities (counties) public security traffic management bureau, land planning bureau, municipal public security bureau, city management committee, the industrial and commercial bureau, financial administration, economic and information commission, development, and reform commission and other departments jointly establish regulatory sandbox specific executive main body, within the scope of the authorization to ensure local sandbox of the orderly conduct of the pilot test, the agency that regulates the sandbox access management and applies for approval, The project 
evaluation should be carried out for the Bike-sharing platform entering the sandbox test, and the test platform should establish a complete user protection mechanism and a data supervision platform for real-time dynamic supervision.

Specifically, the Municipal Traffic Administration Bureau is responsible for drafting local guidelines for the sandbox program, and, based on the pilot situation, jointly compile sandbox access, testing, withdrawal, and other rules with municipal Public Security Bureau and other departments to guide the implementation of the sandbox. It can jointly build a refined and informationized supervision platform with third-party institutions to monitor the release of bicycles.

The municipal Land Bureau is responsible for planning the transport system and supporting facilities for the sandbox pilot. The Municipal Civilization Office is responsible for guiding and informing users who participate in sandbox testing of relevant risks and codes of conduct to protect users' rights and interests. The industry association and the Municipal Consumer Protection Commission shall be responsible for the unification of group standards and enterprise service standards of shared bikes. Local branches of the People's Bank of China, Municipal Development and Reform Commission, Cyberspace Information Office, Municipal Public Security Bureau, Municipal Industrial, and Commercial Bureau, and other departments conduct screening, restraint, and real-time supervision of sandbox test projects following their responsibilities.

All departments cooperate to share data and information, establish a lasting and long-term supervision mechanism, and constantly optimize the testing process. Beijing street grassroots governance can take "street whistled, department report" mode, citizens and street Shared cyclingrelated problem (such as disorderly parking place affect residents' travel and normal life, difficult to refund the deposit property security threats such as users, information fraud issues), need each functional departments promptly to give support and cooperation, Grassroots departments such as street or community quickly "whistle" to the superior information feedback, all relevant departments immediately respond to "report", for specific problems with the street department to solve, and the sandbox test process optimization.[26]

(3) Sandbox test subject requirements

Bike-sharing platforms participating in the sandbox test should clarify the sandbox operation rules and terms in advance, determine whether their projects are suitable for the sandbox test, and submit a written application as required. After passing the qualification examination by the sandbox regulatory authorities, they will get the test opportunity. For example, the China Banking Regulatory Commission and the Financial Services Office should examine the fund operation mode of Bikesharing enterprises to prevent the deposit from being difficult to return. After entering the sandbox, Bike-sharing enterprises should discuss the project test plan with the regulatory body, cooperate with the supervision throughout the whole process, and take the initiative to disclose information and feedback. In case of behaviors and potential risks that may damage users' rights and interests, timely communication with the regulatory authorities and make adjustments. If the platform cannot provide a solution for the time being, timely terminate the project test and exit the sandbox to prevent further spread of risks. After the test, Bike-sharing enterprises should submit a sandbox test summary report to the regulatory body and accept the evaluation. If they pass the evaluation, they will jointly carry out the next market introduction plan with the regulatory body.

Bike-sharing companies participating in the test can jointly build a data-sharing platform to monitor the number of bikes and order distribution in different regions, to have a clear understanding of market demand and reduce vicious competition and waste of resources. For example, The Gulou District of Nanjing has set up a pilot model of "sharing and co-governance", in which three shared bike platforms are jointly responsible for the maintenance and removal of bikes in the area. "They catch them when they go out and then divide them when they come back", increasing management efficiency.[27] Bike-sharing platforms should also design communication channels with users in advance, obtain users' test feedback promptly, and master users' needs to improve their products and services. Can draw lessons from the current sharing short rent platform user experience feedback mode, although is filled with all kinds of problems, the reality, wooden bird represented by the 
platform has a relatively perfect user rating feedback path, again on the third party assessment institutions, overall service information is relatively open and transparent, the platform can be adjusted according to the market, users also have a wide variety of choices, In 2017, the customer satisfaction of the whole shared short-term rental industry reached $89.3 \%$, and the intention to repeat booking exceeded $93 \%$. Bike-sharing platforms should also actively explore the application of digital technologies such as virtual fences and tide monitoring to regulate user behavior and regulate the placement and distribution of bikes.

(4) Test user requirements

The users selected for the sandbox test of shared bikes should have the corresponding risk tolerance, and both the regulatory body and the testing body should disclose information before the test to ensure the users' right to know and the right to independently choose and claim for compensation. Strictly protect users' rights and interests through systems, and formulate mandatory standards and protection and compensation schemes, such as the Financial Services Compensation Scheme (FSCS) and Financial Complaints Service (FOS) of the UK.[20]To prepare for possible situations in the test.Test users themselves should also abide by the sandbox rules, cooperate with the regulatory body, and give feedback and suggestions on the products and services of shared bikes promptly so that the regulatory authorities and enterprises can grasp the effects of the specific development of shared bikes in real-time, which is conducive to the adjustment of the policy agenda and sandbox test rules.

\section{Practical Obstacles to the Introduction of a Regulatory Sandbox in Emerging Industries}

Although the advantages of regulatory sandbox have been highlighted in practice, there are still some problems in operation that need attention, which can be divided into two aspects: common problems of the regulatory sandbox and special problems in The Context of China.

On the one hand, there are some common problems in the sandbox operation of supervision in different fields at home and abroad. First of all, the issue of authorization, countries are still difficult to grasp the flexibility of authorization.[28] Some scholars believe that sandbox access should further reduce the compliance cost of enterprises, increase the cost of violations, and avoid causing application barriers.[18] Secondly, the audit period before the start of the test is long and the time cost is high. To avoid risks, the audit time of the existing regulatory sandbox is generally more than half a year. Finally, due to the limited scale and cost of the experiment, both the sandbox and the pilot reform are always constrained by the scope, and the potential risks of many emerging industries may not be fully exposed in the local scope.

On the other hand, although China's regulatory sandbox has only officially been in place for about a year, some specific issues in the Chinese context must be considered in advance. First of all, the responsibilities and powers of regulatory bodies need to be clearly defined, especially between the central and local governments. In the governance of the development of emerging industries, problems such as misplaced responsibility and ambiguity often appear. Secondly, the level of economic development in different regions of China is not balanced, and the regional reconciliation mechanism is not perfect.[29] However, the development of emerging industries often involves multiple departments, crossing the geographical and administrative scope, and it is difficult to define the specific division of authority and cooperation between local governments and functional departments.

\section{Conclusion}

The rapid rise of the emerging industry is playing a more and more important to the promotion of China's innovation ability, high degree of uncertainty and risk in the emerging industry development potential and regulation scale features such as difficult to master the traditional governance model is no longer applicable, government departments should actively introduce adaptive regulation, 
advanced concepts, such as agile governance using the system innovation to guide innovation in emerging industries, The regulatory framework adapted to the development of China's emerging industries is designed by comprehensively using innovation governance tools such as a regulatory sandbox.

This paper draws lessons from the application experience of a regulatory sandbox in different fields at home and abroad, takes the Bike-sharing industry as an example, designs the regulatory sandbox framework of China's emerging industry, and deeply explains the operation mode of sandbox from the perspective of sandbox regulatory subjects, testing subjects, users, and society. Regulatory bodies should follow the principle of multiple objectives, consider innovation and risk control, formulate various rules on access, testing, and withdrawal for emerging industries, and continuously revise them based on test feedback so that projects with substantial innovation can be fully tested based on existing regulatory resources. Moreover, it is necessary to combine digital technology and establish a dynamic supervision mechanism with a long-lasting effect. The test subjects need to cooperate closely with the regulatory authorities, do a good job in information disclosure and feedback, and establish a data-sharing platform within the industry. Publicize the risk and compensation plan to test users and society in advance to protect the rights and interests of users. The government establishes a communication mechanism for multiple stakeholders so that different stakeholders can communicate in time, perceive each other's needs, participate in the setting of policy agenda, and improve the timeliness of policies. At present, the regulation of sandbox is dominated by the government, the future can expand to industry organize set up a complete set of the testing system, before the innovation projects into the market, industry of spontaneous sandbox test, verify the value and reliability of the innovation, form a new industry "industry sandbox", thus better cater to the era development.

\section{References}

[1] The rise and norms of digital economy [J]. Tsinghua Management Review,2019(Z1):88-92.

[2] Xue LAN, Zhao Jing. Towards agile governance: A study on the development and supervision model of emerging industries [J]. Chinese Public Administration,2019(08):28-34.

[3] Mukti Khaire. Fashioning an Industry: Cognitive Processes in the Construction of Worth of a New Industry[J]. Organization Studies,2014,35(1).

[4] Violina P. Rindova, Antoaneta P. Petkova. When Is a New Thing a Good Thing? Technological Change, Product Form Design, Perceptions of Value for Product Innovations[J]. Organization Science,2007,18(2).

[5] Introduction to the SEJ Special Issue on Business Models: Benoit Demil, Xavier Lecocq, Joan E. Ricart, Christoph Zott Strategic Entrepreneurship Journal,2015,9(1).

[6] Jiang X J. Government management and services in the era of big data: Enhancing capacity and coping with challenges [J]. Chinese Public Administration,2018(09):6-11.

[7] Zhao Guanghui, Li Lingling. Regulation of new Transportation Service Business Model in the era of big data: A case study of ride-hailing [J]. Management world,2019,35(06):109-118.

[8] EMA. Regulatory Sandbox Framework Version 2.0 [EB/OL]. https:// www. ema.gov. sg/media_release. aspx? news_sid=20171020Wab84AqS9NXY,2019-9-3.

[9] Liao Fan. Review on the theory and Practice of regulatory sandbox under the background of fintech [J]. Journal of Xiamen University (Philosophy and Social Sciences),2019(02):12-20.

[10] New Finance,2016(10):12-16. (In Chinese with English abstract).

[11] World Economic Forum. Agile Governance: Reimagining Policy-making in the Fourth Industrial Revolution [R], 2018.

[12] IOSCO, IOSCO Research Report on Financial Technologies, Research Report, February 2017.

[13] FCA. Regulatory sandbox lessons learned report[R]. Britain: FCA,2017.

[14] Goo J J, Heo J Y. The Impact of the Regulatory Sandbox on the Fintech Industry, with a Discussion on the Relation between Regulatory Sandboxes and Open Innovation[J]. Journal of Open Innovation Technology Market and Complexity, 2020, 6(2):43. 
[15] Zhang Yiyan. Sandbox System of Supervision in South Korea [J]. Science and Technology China, 2020 (02): 100-101.

[16] Liu G X. Legal reform promoting innovation in Japan: theory, arrangement and inspiration [J]. Science and technology progress and countermeasures,2020,37(18):114-122.

[17] Sweden [EB/OL]. https://www.drivesweden.net,2017.

[18] Sandbox regulation: Introduction of logic and local structure [J]. Southwest Financial,2019(03):53-63.

[19] Zhang Jingzhi. The International Model of "Regulatory sandbox" and the Development path of Mainland China [J]. Financial Regulation Research,2017(05):22-35.

[20] Zhao Jie, Mou Zongjie, SANG Guangliang. Research on international "Regulatory sandbox" model and its enlightenment to China [J]. Financial Development Studies,2016(12):56-61.

[21] Li Dan. Accelerating the launch of the second batch of "Regulatory sandbox" pilot [J]. China Financier, 2020 (07):87-88.

[22] Yang Weizhong, Director of the Operation Management Department of the Central Bank Study and establish the Chinese version of "regulatory sandbox" out of the box standard [EB/OL]. http:// finance. sina. com.cn/China/bwdt/2020-09-08/doc-iivhuipp3226530.shtml, 2020.

[23] China Information and Communication Institute. 2017 Economic and Social Impact Report of Shared bikes. 2018.2.

[24] Guo Peng, Lin Xiang-zhi, HUANG Yi, Tu Si-ming, Bai Xiao-ming, Yang Ya-wen, YE Lin. Journal of public management,2017,14(03):1-10+154.

[25] [EB/OL]. http://www.qgxgw.org. 2016-10-24.

[26] Institutional Analysis on the Reform of Large Department System in Urban Streets --Based on a Case Study of Dongcheng District, Beijing [J]. Yang Hongshan, Shi Jinxin. Journal of Beijing Administration Institute. 2019(02).

[27] Wu Yunqing. "Sharing and Governance" to explore the new path of grassroots management [N]. Nanjing Daily, 2019-12-24(A04).

[28] Liu Liang, Zou Jia jia. Regulatory sandbox: Foreign Application and Localization [J]. Southwest Finance, 2020 (05):17-24.

[29] Ma Nan. Related issues and construction ideas of supervision sandbox construction in Guangdong-Hong Kong-Macao Greater Bay Area [J]. Southern Finance,2020(07):3-12. 